\title{
ADOLESCENTES EM CONFLITO COM A LEI E DIREITOS HUMANOS: desafios para
} implementação do SINASE

\author{
Aurora Amélia Brito de Miranda \\ Universidade Federal do Maranhão (UFMA) \\ Beatriz Gershenson Aguinsky \\ Pontifícia Universidade Católica do Rio Grande do Sul (PUC-RS) \\ Cândida da Costa \\ Universidade Federal do Maranhão (UFMA) \\ Lisélen de Freitas Avila \\ Pontifícia Universidade Católica do Rio Grande do Sul (PUC-RS) \\ Maria Jacinta Jovino Carneiro da Silva \\ Universidade Federal do Maranhão (UFMA) \\ Selma Maria Muniz Marques \\ Universidade Federal do Maranhão (UFMA)
}

ADOLESCENTES EM CONFLITO COM A LEI E DIREITOS HUMANOS: desafios para implementação do SINASE

Resumo: O artigo trata das inovações da legislação brasileira na política de atendimento socioeducativo aos adolescentes em conflito com a lei (SINASE), destacando avanços e desafios. Examina o papel da proteção social especial da Política de Assistência Social e do SUAS na execução das medidas socioeducativas. Tem como referência a pesquisa do Estado do Maranhão (UFMA), articulada ao Mapeamento Nacional do Atendimento Socioeducativo (SDH/PR/CONANDA) e as reflexões da equipe da PUCRS. Afirma diferentes questões a serem enfrentadas pelo atendimento socioeducativo, tais como: o reduzido número e a baixa qualificação dos recursos humanos; a incipiente articulação entre atores do Sistema de Garantia de Direitos; a ausência de intersetorialidade entre as políticas públicas e o reduzido financiamento para as medidas socioeducativas.

Palavras-chave: Atendimento socioeducativo, direitos humanos, Política de Assistência Social, adolescentes

ADOLESCENTS IN CONFLICT WITH THE LAW AND HUMAN RIGHTS: challenges to SINASE implementation.

Abstract: The article discusses the innovations of Brazilian legislation on social educational care policy to adolescents in conflict with the law (SINASE), highlighting advances and challenges. It examines the role of the special social protection of Social Assistance Policy and the SUAS in the execution of social educational measures. Taking as reference the research of the State of Maranhão (UFMA), articulated to the national Mapping of Social Educational care (SDH /PR/CONANDA) and the reflections of the team of PUCRS. Different issues are affirmed to be faced by Social Educational care, such as: the reduced number and the low qualification of human resources; the incipient articulation between actors of the System of Guaranteed Rights; the absence of intersectoral collaboration among public policies and the reduced funding educative measures.

Keywords: Social and educational care, human rights, Social Assistance Policy, adolescents. 

Jovino Carneiro da Silva e Selma Maria Muniz Marques

\section{INTRODUÇÃO}

A política de atendimento socioeducativo delineou-se a partir do Estatuto da Criança e do Adolescente (ECA), por meio de um conjunto de parâmetros, normativas e proposições, sendo-lhe acrescidas, posteriormente, maiores detalhamentos e especificações por meio da Resolução nº 119 do Conselho Nacional dos Direitos da Criança e do Adolescente (CONANDA), que editou o Sistema Nacional de Atendimento Socioeducativo (SINASE) e culminou com a Lei 12.594/12, que instituiu o SINASE.

Foi somente no final da década de 1990 que o atendimento socioeducativo passou a ser destinatário de um conjunto de parâmetros, normativas e proposições que progressivamente passaram a conformar o campo da Política de Atendimento Socioeducativo, tal como pode ser compreendida atualmente, com as orientações e regulamentações do SINASE. Destaca-se sua estreita articulação institucional com a Política de Assistência Social, principalmente pela proteção social especial, visto que o SUAS é responsável pela execução das medidas socioeducativas em meio aberto, através de um serviço especializado do Centro de Referência Especializado de Assistência Social (CREAS); e em meio fechado, através dos serviços das unidades de atendimento socioeducativo, de gestão dos municípios ou do Estado.

A partir do Mapeamento Nacional sobre a situação do Atendimento Socioeducativo no Brasil (SDH/PR), no qual se inseriu as pesquisas realizadas pela UFMA e PUC/RS, são apresentadas as análises dos dados levantados nas Unidades, junto ao Sistema de Garantia de Direitos Humanos de Crianças e Adolescentes (SGDHCA), famílias e adolescentes. As informações das pesquisas possibilitaram a identificação do universo dos problemas e dilemas que gestores, profissionais e adolescentes - em conflito com a lei - enfrentam no processo socioeducativo.

Neste artigo, apresentam-se as principais questões e desafios postos ao atendimento dos adolescentes em conflito com a lei, corroborando os princípios e diretrizes previstos SINASE.

\section{A POLÍTICA DE ATENDIMENTO SOCIOEDUCATIVO E O ADOLESCENTE EM CONFLITO COM A LEI: diretivas do ECA e do SINASE}

O ECA assenta-se sobre o conceito de proteção integral, a partir do qual, aos menores de 18 anos, são destinadas medidas preventivas, socioeducativas e protetivas. Os inegáveis avanços do ECA estão associados ao reconhecimento de crianças e adolescentes como sujeitos de direitos e sua inscrição no circuito dos direitos humanos, colocando em cena a possibilidade de defesa destes direitos já que, até então, não estavam disponíveis mecanismos eficazes no enfrentamento à discriminação, negligência e violência.

A Constituição Federal, em seu artigo 228, estabelece que a idade penal inicia-se a partir dos 18 anos, ficando os menores de idade inimputáveis perante a lei. As crianças até 12 anos, ao se envolverem em ato infracional, receberão medidas protetivas, enquanto os adolescentes poderão tanto receber medidas protetivas, quanto socioeducativas.

O ECA obriga e responsabiliza condutas contrárias, adversas ao ordenamento jurídico por meio das medidas socioeducativas. Estas medidas, aplicadas, por ordem judicial, a adolescentes que tenham praticado ato infracional, têm por objetivos a responsabilização do adolescente quanto às consequências lesivas do ato infracional; a sua integração social do adolescente e a garantia de seus direitos individuais e sociais; e a desaprovação da conduta infracional (BRASIL, 2012). Tais medidas são aplicadas levando-se em conta a capacidade do adolescente em cumprir determinada medida, as circunstâncias que sucedeu o suposto ato infracional e a gravidade deste (BRASIL, 1990); além de possuirem finalidades especificamente educativas e pedagógicas.

O ECA, para atender os direitos do adolescente em conflito com a lei, condicionou-o a três princípios mestres: o da brevidade, em relação ao tempo necessário para que o adolescente submeta-se ao poder punitivo do estado; o da excepcionalidade, sendo a medida de privação de liberdade a última alternativa a ser aplicada; e o respeito à condição peculiar de pessoa em desenvolvimento (ISHIDA, 2009), os quais foram reafirmados pela lei do SINASE.

Desta forma, a aplicação das medidas socioeducativas representa a intervenção do Estado frente aos atos infracionais praticados por adolescentes, observando os direitos que lhes são garantidos, considerando-os como sujeitos em situação peculiar de desenvolvimento e que gozam de absoluta prioridade na efetivação de seus direitos fundamentais (BRASIL, 2009), enquanto sujeito de direitos. A Resolução $n^{\circ} 119$, de 11 de dezembro de 2006, elaborada pelo CONANDA, dispõe sobre - SINASE. É fruto de uma construção coletiva entre os operadores do Sistema de Garantia de Direitos Humanos de Crianças e Adolescentes. Após seis anos da vigência da Resolução, entrou em vigor a Lei 12.594/2012, que instituiu o SINASE, reforçando parâmetros existentes para a socioeducação e introduzindo novos elementos.

A conquista do direito ao atendimento socioeducativo sob a perspectiva da responsabilização estatutária, em contraposição à ideia de mera retribuição e punição aos adolescentes em conflito com a lei, é ainda recente e remonta aos marcos da Convenção sobre os Direitos da Criança e do Adolescente (1989) e do 
ECA (1990). Na ótica da Convenção, o atendimento das medidas socioeducativas deve orientar-se pelo estímulo à educação em direitos humanos e respeito às liberdades fundamentais, visando um desempenho positivo na sociedade e, do Estatuto, às necessidades pedagógicas dos adolescentes (ECA, 1990, art. 113).

No entanto, como conquista recente, é um direito traspassado pela luta histórica dos direitos humanos na qual se considera que os direitos se encontram em permanente reafirmação, ora conquistando espaço, ora sendo comprimidos por interesses contrários à doutrina de proteção integral das crianças e adolescentes.

A Lei do SINASE é um conjunto ordenado de princípios, regras e critérios, de caráter jurídico, político, pedagógico, financeiro e administrativo que abarca desde o processo de apuração do ato infracional, até a execução da medida socioeducativa, suprindo algumas lacunas ainda existentes do ECA e à Resolução do CONANDA, reafirmando o caráter pedagógico das medidas socioeducativas, sem negar a natureza sancionatória das medidas, em seu cumprimento.

Conforme disposto no artigo 35 do ECA, a execução das medidas socioeducativas regerse-á por meio dos seguintes princípios: legalidade; excepcionalidade; prioridade a práticas ou medidas de caráter restaurativas; proporcionalidade em relação à ofensa cometida; brevidade da medida em resposta ao ato cometido, em especial o respeito ao que dispõe o art. 122 do ECA; individualização; mínima intervenção; não discriminação do adolescente; e fortalecimento dos vínculos familiares e comunitários no processo socioeducativo (BRASIL, 2012).

O processo de municipalização das medidas socioeducativas, em curso no país, especialmente no Rio Grande do Sul e no Maranhão, desde meados dos anos 2000, encontra-se atrelado aos avanços das concepções ampliadas de proteção social, asseguradas nos arcos de uma Política deAssistência Social no Brasil. Nestes marcos, novos desafios se apresentam para o atendimento socioeducativo em meio aberto a partir da implementação do SUAS.

3 O SUAS E AS MEDIDAS SOCIOEDUCATIVAS: o Serviço de Proteção Social a Adolescentes em Cumprimento de MSE

APolítica deAssistência Social, ao serinstituída como direito, nos moldes da Constituição Federal e da LOAS, representou um avanço significativo na construção da proteção social, principalmente para a grande parcela da população que não tem condições mínimas para garantir a sobrevivência sem a intervenção do Estado. A proteção social da Política de Assistência Social refere-se a um conjunto de programas, projetos, ações, atenções, benefícios e serviços socioassistenciais ofertados pelo SUAS. Tem como objetivo a redução e a prevenção das situações de vulnerabilidades sociais, de impedimento de satisfação das necessidades básicas, de negação da dignidade humana, de risco social e pessoal, de violação de direitos.

A proteção social especial da Política de Assistência Social é direcionada a pessoas, famílias ou grupos em situação de risco pessoal e social, exclusão e violação de direitos, como crianças, adolescentes, jovens, idosos, pessoas com deficiência e em situação de rua, uso abusivo de substâncias psicoativas, migrantes, etc. Sua efetivação não está limitada ao reconhecimento da legitimidade pública das demandas, mas implica, necessariamente, no direito à efetivação dos direitos, como parte da construção de uma cultura de justiça e de respeito à dignidade humana.

O SUAS é um sistema público, descentralizado e participativo, que tem por função a gestão do conteúdo específico da proteção social da Política de Assistência Social brasileira. Deve garantir a materialização dos direitos socioassistenciais e de outros conteúdos contemplados na LOAS (PNAS, 2004, p. 27). Os CREAS fazem parte da estrutura do SUAS e são responsáveis pela proteção social especial de média complexidade, através de cinco serviços socioassistenciais, dentre os quais destaca-se um diretamente vinculado à Política de Atendimento Socioeduactivo: o Serviço de Proteção Social a Adolescentes em Cumprimento de MSE, em meio aberto, (Liberdade Assistida e Prestação de Serviço à Comunidade).

Os CREAS devem prover a proteção social especial, com atendimento e acompanhamento aos adolescentes, através do Serviço de Proteção Social a Adolescentes em Cumprimento de MSE de LA e PSC visando a garantia do acesso aos seus direitos e a ressignificação de valores em todas as dimensões de suas vidas. No acompanhamento, deve ser elaborado o Plano Individual de Atendimento (PIA), fixando objetivos e metas a serem alcançados durante o cumprimento da medida socioeducativa e na vida futura, com a participação do adolescente e da família.

De acordo com a PNAS (2004) e com a NOB/SUAS (2005), os serviços relativos às medidas socioeducativas restritivas e privativas de liberdade - semiliberdade, internação provisória e sentenciada, devem ser ofertados para cada medida e por sexo dos adolescentes. Devem ser oferecidos pelos municípios, dependendo do nível de gestão a que estão habilitados e seguindo a descentralização do SUAS e do SINASE. Porém, a maioria dessas unidades ainda está sob a responsabilidade das organizações governamentais que coordenam a Política de Assistência Social, ao nível da gestão estadual (SILVA, 2012, p. 344).

Entretanto, na Tipificação Nacional dos Serviços Socioassistenciais, as MSE restritivas e privativas de liberdade não aparecem no conteúdo 

Jovino Carneiro da Silva e Selma Maria Muniz Marques

do documento, sob nenhuma forma, embora estejam explicitadas no ECA, na PNAS de 2004 e no SINASE, no âmbito da Secretaria de Direitos Humanos (SDH). Pode-se afirmar que a ausência das MSE restritivas e privativas de liberdade, no discurso padronizador da Tipificação Nacional indica um não-dito, segundo Foucault (2005).

\section{OS DIREITOS DOS ADOLESCENTES EM CONFLITO COM A LEI NO SISTEMA DE ATENDIMENTO SOCIOEDUCATIVO}

Ao infringir a lei, um adolescente pode ser privado parcial ou integralmente do direito de ir e vir; seus demais direitos não só continuam invioláveis, como passam a ser resguardados pelo Estado.

A abordagem dos direitos humanos pode ser feita por várias vias. $\mathrm{Na}$ brevidade deste texto e optando pela via da indivisibilidade dos direitos humanos. Nesse sentido, trazemos Benevenuto (2001), que classifica os direitos econômicos, sociais e culturais no escopo dos direitos humanos. $\mathrm{O}$ autor identifica caminhos distintos (ilustrados com exemplos práticos) para a realização dos direitos econômicos, sociais e culturais, a saber: o caminho legal (elaboração legislativa e justiciabilidade), o caminho das políticas públicas e sociais (incluindo as chamadas ações afirmativas) e o caminho do monitoramento de metas progressivas.

Nessa direção, poder-se-ia falar de um núcleo fundamental de direitos econômicos, sociais e culturais, a ser constituído, por exemplo, pelos direitos ao trabalho, à saúde e à educação (mais além dos chamados direitos de subsistência, tais como o direito à alimentação, o direito a moradia, e o direito a cuidados médicos).

Entretanto, nos defrontamos com uma grande dificuldade que nos desafia: como assegurar esses direitos num mundo em que a soberania das nações se acha ameaçada e enfraquecida frente ao poderio econômico de empresas multi ou transnacionais, em que o conceito de cidadania tem sido esvaziado e que o Estado tem se retraído em sua atuação nas áreas sociais? Em um mundo no qual o desrespeito aos direitos humanos e a ampliação da violência na vida social têm sido marcas constantes?

\subsection{A socioeducação no Estado do Rio Grande do Sul: as Medidas Socioeducativas em Meio Aberto e Fechado}

A partir do Mapeamento do Sistema Socioeducativo de Privação de Liberdade no Estado do Rio Grande do Sul, identificou-se um número total de 1.079 adolescentes e jovens, com idades entre 12 e 20 anos (sobretudo entre 17 e 18 anos), cumprindo medidas socioeducativas de privação de liberdade no Estado, predominantemente do sexo masculino (96\%). Desta população, $60 \%$ são brancos; $16 \%$ pretos; $24 \%$ pardos; e $1 \%$ indígena.
Verificou-se a existência de adolescentes e jovens com deficiência física e visual, além de algum tipo de déficit intelectual. $O$ quadro dos adolescentes e jovens privados de liberdade remete para a situação da vulnerabilidade social das famílias a que pertencem, pois, em sua grande maioria, subsistem com uma renda familiar inferior a 2 salários mínimos $(78,71 \%)$.

Com relação à escolaridade, a maioria dos adolescentes encontra-se no ensino fundamental $(80,02 \%)$, até a $4^{\text {a }}$ série $(35,62 \%)$ e de $5^{\text {a }}$ a $8^{\text {a }}$ séries $(44,40 \%)$, verificando-se, ainda, que a maior parte destes sujeitos não estava frequentando a escola antes do ingresso na privação de liberdade $(74,82 \%)$. No que concerne à situação ocupacional dos adolescentes antes do ingresso na FASE, tem-se que $44,48 \%$ tinham alguma ocupação, com predomínio do exercício de trabalho informal $(42,37 \%)$.

No que tange às drogas, constatou-se a presença do uso de múltiplas substâncias psicoativas em concomitância pelos adolescentes, com predominância do crack $(35,91 \%)$ e maconha $(35,91 \%)$. Quanto ao tipo de ato infracional praticado pelos adolescentes e jovens, tem-se o roubo como tipo penal mais presente $(49,46 \%$ das ocorrências), seguido por homicídios (8,66\%). Entre as meninas, a maior incidência do tipo penal é de tráfico de drogas $(1,15 \%)$. Verifica-se que a maior parte dos adolescentes e jovens encontra-se em sua primeira internação $(58,72 \%)$.

Percebe-se que 0 maior número de adolescentes na FASE-RS é oriundo do juizado de Porto Alegre $(48,3 \%)$, seguido de Novo Hamburgo $(10,4 \%)$ e Caxias do Sul $(9,0 \%)$. Constata-se que dentre as medidas privativas de liberdade, a Semiliberdade ainda é uma medida socioeducativa pouco utilizada na realidade gaúcha $(5,58 \%)$.

Com relação à situação das unidades de privação de liberdade, o mapeamento identificou a existência de 16 unidades de aplicação de medida socioeducativa em meio fechado no RS. Sinalizase a existência de apenas uma única unidade de atendimento para meninas em todo o Estado, que atende desde medidas sem possibilidades de atividade externa até medidas de semiliberdade. 0 fenômeno da superlotação está presente tanto nas unidades da capital, quanto do interior. A maioria das unidades $(80 \%)$ não apresenta ambiente físico adequado às necessidades da proposta pedagógica de aplicação da medida socioeducativa. Os problemas variam desde a inexistência de espaços para desenvolvimento de atividades esportivas e de convivência, até o péssimo estado de manutenção e higiene de algumas unidades, abrigando adolescentes em condições subumanas. Verifica-se a existência de alas de isolamento, também denominadas em algumas unidades de "sala de reflexão".

No que se refere à educação escolar, o mapeamento mostrou que, do total de unidades 
pesquisadas, 100\% oferecem Ensino Fundamental aos adolescentes privados de liberdade, sendo que a maioria das instituições que oferecem este nível de ensino o faz por meio da inserção de escolas públicas dentro das unidades, em geral oferecendo o ensino regular. Entre as outras formas adotadas para a garantia da educação escolar, destacam-se a frequência em escolas públicas fora da unidade (semiliberdade e internação com possibilidade de atividade externa); o reforço escolar, oferecido, em geral, para a prestação de exames supletivos.

Quanto à profissionalização, $62,5 \%$ das unidades oferecem ações de profissionalização aos adolescentes em medida de privação de liberdade, em sua maioria de forma não sistemática e sem inserção em uma política estadual de profissionalização, estando vinculadas, ainda, ao critério de bom comportamento. Da mesma forma, a retirada do adolescente destas atividades é vista como punição a algum comportamento ou ato julgado pela equipe técnica como não adequado. Foi apontada também, a realização de cursos que não têm uma contribuição significativa para a qualificação profissional do adolescente, tais como artesanato e afins, considerados apenas como ocupacionais.

Com relação à saúde, das unidades pesquisadas, $15 \%$ afirmaram utilizar apenas os serviços da saúde pública local, $85 \%$ têm profissionais pagos com recursos próprios, e em uma unidade foi respondido que há equipe do SUS dentro da unidade. Destaca-se como uma das principais dificuldades a ausência de tratamento para adolescentes usuários de drogas. Outra questão importante a ser considerada na saúde dessa população é o excesso de medicação a que são submetidos os internos em algumas unidades. $O$ atendimento nas unidades do Estado do Rio Grande do Sul é composto por um serviço terceirizado de psiquiatras, que se de um lado é garantia de atendimento, também reflete o viés terapêutico presente na execução da medida, através da medicalização como um mecanismo sancionatório, em detrimento de práticas socioeducativas.

O acesso a esporte, lazer e cultura, conforme disposto no ECA e no SINASE, é garantido em todas as unidades visitadas. Observa-se que em todas as unidades há estímulo para atividades físicas e inserção em atividades culturais. Grande parte desenvolve atividades esportivas dentro da própria unidade, mas apenas disponibilizam os equipamentos existentes, como quadras e salas de jogos, durante o tempo destinado à recreação. Nem sempre existem profissionais disponíveis para a coordenação das atividades, mas é bastante mencionada a presença de professores de educação física. As atividades externas parecem ser as que enfrentam mais dificuldades para a sua realização. Além da necessidade de transporte e segurança, muitos adolescentes não têm autorização para sair da unidade.
Quanto à convivência familiar e comunitária, todas as unidades pesquisadas relatam que a proposta pedagógica desenvolvida incentiva a participação da família ou de pessoas com as quais o adolescente possui vínculo afetivo no processo socioeducativo. Com relação à visita íntima, a mesma é negada em todas as unidades de privação de liberdade do Estado, sendo justificada como um problema gerador de conflitos entre os adolescentes e por não ter estrutura física adequada.

No que se refere ao corpo técnico, o atendimento nas unidades é composto pela equipe de técnicos e socioeducadores. Porém, registra-se um número reduzido de profissionais em relação ao parâmetro sobre a composição da equipe mínima de atendimento nos casos de internação definido pelo SINASE. Os únicos casos onde existe adequação ao previsto pelo SINASE, referem-se às unidades de semiliberdade.

No que concerne ao acesso à assistência jurídica, em $77 \%$ das unidades pesquisadas no RS há a disponibilidade de advogados para acompanhamento jurídico, mesmo que essa disponibilidade seja relativa, sendo comuns os relatos de o advogado ser designado apenas para comparecimento em audiências, tomando conhecimento do processo poucas horas antes do início destas.

Em relação à articulação do Sistema de Garantia de Direitos da Infância e Juventude (SGD) com o Programa Socioeducativo de Privação de Liberdade, aponta-se como um dos principais avanços a implantação de uma política estadual específica para o atendimento das medidas socioeducativas, com a implementação de serviços especializados, como por exemplo, da Delegacia Especializada da Criança e do Adolescente (DECA). Dentre as deficiências desta articulação, são mencionadas questões como falta de recursos humanos especializados nas unidades de atendimento da FASE; falta de vagas para internação com privação de liberdade; falta de planejamento e acompanhamento para os egressos do sistema de privação de liberdade; grande dificuldade de sintonia entre as diversas instâncias e atores envolvidos no SGD. Além disso, o desconhecimento do SINASE ainda é uma realidade para alguns atores do SDG no Estado.

Quanto à qualidade do atendimento, observase que ainda são apontadas necessidades de melhores condições e qualidade no atendimento dos adolescentes em conflito com a lei. A adoção de um sistema de atendimento das medidas socioeducativas que esteja em perfeita consonância com os preceitos legais, é uma luta antiga. Com relação aos parâmetros da qualidade de atendimento orientados pelo SINASE, observa-se que ainda há discrepância entre os municípios pesquisados, havendo conhecimento e adaptação progressiva em alguns locais do Estado. 

Jovino Carneiro da Silva e Selma Maria Muniz Marques

A partir do estudo sobre a Municipalização das Medidas Socioeducativas em Meio Aberto no Estado do Rio Grande do Sul, identificou-se um número estimado de 893 adolescentes e jovens, com idades entre 12 e 21 anos (sobretudo entre 15 e 18 anos), cumprindo medidas socioeducativas em meio aberto, no Estado, predominantemente do sexo masculino (88\%). Quanto ao quesito raça/ etnia, desta população, 64,59 são brancos; $20,51 \%$ se consideram pardos; $14,16 \%$ negros; $0,61 \%$ amarelos; e 0,12\% são indígenas. A maior parte das famílias dos adolescentes que cumprem medidas socioeducativas em meio aberto subsistem com uma renda familiar inferior a 2 salários mínimos (57\%).

Com relação à escolaridade destes adolescentes e jovens, a maior concentração encontra-se no ensino fundamental $(76,61 \%)$, até a $4^{\mathrm{a}}$ série $(18,77 \%)$ e de $5^{\mathrm{a}}$ a $8^{\mathrm{a}}$ séries $(58,84 \%)$. Verifica-se que a maior parte destes sujeitos $(57,06 \%)$ não estava frequentando a escola antes do cumprimento da medida socioeducativa de meio aberto.

Quanto ao uso de drogas, constatou-se a presença do uso de múltiplas substâncias psicoativas em concomitância pelos adolescentes. Verifica-se que o consumo de maconha é responsável por $31 \%$ das ocorrências de uso de drogas, seguidos por crack $(24 \%)$, álcool $(23 \%)$ e cocaína (14\%).

No que se relaciona ao tipo de ato infracional praticado pelos adolescentes e jovens, tem-se o roubo como tipo penal mais presente (16\%), seguido por tráfico de drogas e furto (ambos com 14\%) e agressão/lesão corporal (13\%). Verifica-se que a maior parte dos adolescentes e jovens encontra-se em sua primeira medida socioeducativa $(53,09 \%)$.

Com relação à situação dos programas de execução de medidas socioeducativas em meio aberto de LA e PSC no Estado do RS, foram identificadas 21 unidades de atendimento, as quais compõem um quadro ainda bastante heterogêneo no Estado. Convivem distintos arranjos institucionais, sendo que coexistem municípios executando as medidas de meio aberto por meio de iniciativas do executivo municipal, através dos CREAS, por meio do Serviço de Proteção Social a Adolescentes em Cumprimento de Medidas Socioeducativas em Meio Aberto. Outras estratégias são através de parcerias entre o município e ONG's.

As unidades que executam serviços de medidas socioeducativas em meio aberto são em sua maioria CREAS, porém as equipes técnicas (compostas por assistentes sociais, psicólogos, advogados e educadores sociais) atendem não apenas este serviço, como também os demais serviços ofertados neste espaço. Estas, em sua maioria, acompanham mais de 20 adolescentes, contrariando os parâmetros previstos no SINASE sobre a composição mínima do quadro de pessoal para o atendimento socioeducativo de meio aberto. Além disto, os espaços disponibilizados dentro destas unidades para os atendimentos individidual e grupal apresentam, em sua grande maioria, estruturas precárias e recursos materiais escassos.

A necessidade do fortalecimento da rede de atendimento bem como da articulação entre - SGD é apontada como fundamental para a efetivação do atendimento socioeducativo na sua integralidade, bem como para a materialização das políticas públicas e sociais na garantia de direitos humanos e proteção integral dos adolescentes em cumprimento de medidas socioeducativas. Tal fortalecimento exige a qualificação da política de atendimento socioeducativo no que tange a recursos orçamentários, materiais e humanos, além de qualificação e capacitação permanente do quadro de recursos humanos (política de formação de recursos humanos).

Corroborando com os princípios e diretrizes previstos na nova Lei do SINASE para o atendimento socioeducativo, afirma-se, ainda, a necessidade de composição interdisciplinar da equipe técnica; de articulação e intersetorialidade entre as políticas públicas; de clareza da concepção e sentido das medidas socioeducativas; de conhecimento acerca da Lei do SINASE; de integração das três esferas governamentais no tocante à execução das medidas socioeducativas e o atendimento socioeducativo na sua integralidade, a partir de seus respectivos planos socioeducativos, conforme previsto no SINASE.

\subsection{A socioeducação no Estado do Maranhão:} as medidas socioeducativas em Meio Fechado

A Pesquisa Estadual sobre o Sistema de Atendimento Socioeducativo no Estado do Maranhão (período de 2006 a 2008) objetivou fornecer aos gestores públicos da política de atendimento socioeducativo, aos conselhos e à sociedade civil em geral, um quadro do sistema socioeducativo no estado. Para isso, a pesquisa analisou o perfil dos adolescentes atendidos, a situação das unidades de execução das medidas de privação de liberdade e as articulações institucionais que compõem a política de atendimento ao adolescente em conflito com a lei (COSTA et al, 2008).

Sobre a organização e articulação do sistema socioeducativo em nível estadual em relação à aplicação das medidas socioeducativas, a FUNAC, executora estadual das medidas socioeducativas em meio fechado, tem estabelecido termos de cooperação com municípios para financiar e dar assistência técnica para a execução das medidas socioeducativas em meio aberto (Liberdade Assistida e de Prestação de Serviços à Comunidade).

O Estado do Maranhão encontrava-se com cinco Unidades de Atendimento Socioeducativo em Meio Fechado: uma unidade de internação masculina em São José de Ribamar (Centro de Juventude Esperança, com capacidade de atendimento para 40 adolescentes) uma unidade de 
internação mista feminina, em São Luis (o Centro de Juventude Florescer, com capacidade para atendimento de 10 adolescentes), duas Unidades de Semiliberdade, uma em São Luis (Centro de Juventude Nova Jerusalém, com capacidade de atendimento de 20 adolescentes) e outra em Imperatriz (Centro de Juventude Cidadã, com capacidade de atendimento de 8 adolescentes); e duas unidades de atendimento em medida cautelar, uma em São Luis (Centro de Juventude Canaã, com capacidade de atendimento de 30 adolescentes) e outra em Imperatriz (Centro de Juventude Semear, com capacidade para atender 20 adolescentes). A situação de lotação nas unidades encontrada foi: 49 na internação masculina, 04 na internação mista feminina, 21 na semiliberdade masculina e 58 na internação provisória. Assim, quando da realização da pesquisa estavam com lotação, para além da capacidade: a internação masculina e a unidade de internação provisória.

As Unidades funcionam em instalações físicas precárias e sem a estrutura exigida. A Unidade que apresentava as melhores instalações era o Centro de Juventude Canaã. Os direitos assegurados aos adolescentes foram: registro civil, escolarização, qualificação profissional, atividades de lazer, atendimento de saúde. Entretanto, destaca-se que sobre a oferta da escolarização, segurança, atendimento de saúde e qualificação profissional foram apontados indícios da baixa qualidade dos serviços prestados, pois estavam em desacordo com os preceitos do SINASE.

Sobre a educação, apenas uma das Unidades de Internação Provisória não oferece. Como principais dificuldades, foram apontadas no processo de escolarização: a) resistência dos profissionais em relação ao público-alvo; b) distorção idade-série dos adolescentes; c) grande número de adolescentes não alfabetizados; c) resistência dos adolescentes; d) inadequação da metodologia usada.

As atividades de profissionalização têm como pontos fortes a participação dos adolescentes no planejamento das atividades e o levantamento de sugestões e motivações dos adolescentes sobre os cursos que querem. Como principais dificuldades, aparecem: a) nem sempre são encontrados instrutores com a metodologia adequada ao público; b) os espaços para profissionalização ainda estão em fase de estruturação; c) há resistência dos profissionais que não têm a compreensão e foco nos aspectos pedagógicos, predominando uma visão coercitiva, repressora.

Os serviços de saúde estão organizados com enfermarias de pequeno porte, com presença do auxiliar de enfermagem. Em situações mais graves recorrem à rede pública de saúde. Quando os adolescentes usuários de substâncias psicoativas (90 se autodeclararam dependentes químicos) apresentam depressão e crise de abstinência, recorrem ao Hospital Psiquiátrico Nina Rodrigues, em São Luís, entretanto os profissionais das Unidades consideraram o atendimento ineficaz por não promover a recuperação ou tratamento para a dependência química.

Os atores do SGDHCA registram diversas situações de violação de direitos humanos dos adolescentes em cumprimento de medidas socioeducativas, tais como: a ocorrência de nove casos de homicídios dentro da unidade nos últimos 10 anos; a violência física de monitores contra os adolescentes em fugas e rebeliões; a violência psicológica de monitores contra adolescentes, através de xingamentos e humilhações; a não observância à diretriz de separação de adolescentes, considerando a idade, a compleição física e a gravidade do ato infracional; o isolamento em cela sem luz nem ventilação; o cumprimento das medidas além do tempo aplicado; a permanência de adolescentes em cadeias ou delegacias comuns; a infraestrutura deficitária nas delegacias especializadas e o afastamento do convívio familiar.

No que se refere à existência de adolescentes em internação provisória além de 45 dias, os diversos atores do SGD informaram que a ultrapassagem dos 45 dias para a internação provisória é recorrente no Maranhão, especialmente nos municípios do interior do estado, pela ausência de delegacias especializadas. Existem Delegacias do Adolescente Infrator (DAÍ) apenas em São Luis e Imperatriz.

No eixo defesa e responsabilização, ressaltaram que apenas os municípios de São Luís, Imperatriz e São José de Ribamar instalaram as promotorias e juizados da infância e da juventude; destacaram, também, a pequena infraestrutura da Defensoria Pública. Esse cenário sedimenta a visão da maioria dos entrevistados de que há prejuízo do acompanhamento processual dos adolescentes na maioria dos municípios do Estado, bem como no acompanhamento da situação dos adolescentes quando do cumprimento das medidas socioeducativas.

No que se refere ao eixo de controle social, registra-se o aumento do número de Conselhos de Direitos no estado. No Maranhão, com 217 municípios, estão criados e instalados CMDCA's em 157 , existindo $28 \%$ de municípios sem conselhos de direitos. Quanto aos Conselhos Tutelares, eram 112 instalados que em 2012 passaram a não existir em apenas 03 municípios. É patente a debilidade dos organismos na formulação e controle das políticas de proteção à criança e ao adolescente. Foram apontadas várias dificuldades encontradas pelos Conselhos para efetivar o controle social, envolvendo pouca infraestrutura, déficit de recursos humanos, reduzida capacidade técnica para exercício da função, deficiências estruturais e financeiras, bem como dificuldades para descentralizar as ações.

No eixo da promoção de direitos, situam-se as maiores críticas. Há várias debilidades na execução das políticas de saúde, educação, habitação, 
cultura, esporte, lazer, trabalho e assistência social. Inexiste a retaguarda necessária no terreno das políticas públicas (estrutura, intersetorialidade, cobertura) para garantir o adequado atendimento das necessidades dos adolescentes, inclusive na capital, São Luís.

Em relação à visão dos atores do SGDHCA sobre as principais deficiências no atendimento socioeducativo em meio fechado, de forma geral, indicaram: que há descontinuidade da política; que não se configura como política de Estado, mas de governo, cuja mudança gera solução de descontinuidade da política de atendimento socioeducativo, principalmente nos municípios; inadequação dos prédios, não reformulação do projeto pedagógico, não recomposição da equipe técnica; não descentralização das medidas socioeducativas; não existência de delegados de carreira na maioria dos municípios, nível de reincidência e a não organização do SGD no Estado. Para estes, essa situação também é agravada pela ausência de varas e promotorias especializadas nos municípios.

$\mathrm{Na}$ visão do CEDCA/MA, as determinações macroestruturais atuam como impeditivo para a efetivação dos direitos do adolescente em conflito com a lei, ao ser priorizada a política econômica em detrimento das políticas sociais. De forma geral, aparecem vários pontos de estrutura inadequada na percepção do CEDCA/MA, do CDMP, do Ministério Público, do Fórum DCA e do SINDSFUNAC, os quais assinalam: que a estrutura física das Unidades não é adequada ao padrão do adolescente e que são precárias as condições físicas dos prédios. Tais condições, na visão dos representantes do SINDSFUNAC, têm tido como resultado o oposto do que se espera do processo de socioeducação, concorrendo para a brutalização dos adolescentes.

\section{CONCLUSÃO}

A Socioeducação apresenta inúmeras tensões e contradições que repercutem na garantia do acesso aos direitos dos adolescentes em conflito com a lei. Diante deste contexto, diversos são os desafios que se colocam para a garantia da promoção, proteção e defesa dos direitos destes adolescentes. $\mathrm{Na}$ pesquisa em tela, alguns desafios são destacados: o nível de vulnerabilidade social dos adolescentes no atendimento socioeducativo; a distância entre os direitos conquistados e assegurados através do ECA e da Lei Federal do SINASE e a realidade institucional do atendimento socioeducativo, em particular no Maranhão, com sinais sugestivos de falência devido a baixa efetividade em relação aos princípios e parâmetros instituídos pelo SINASE.

A socioeducação constitui-se um campo que demanda um diálogo direto com os direitos humanos. O atendimento socioeducativo exige a garantia de princípios como o respeito à dignidade humana, à liberdade, justiça, igualdade e tolerância. No âmbito da Política de Assistência Social e da Política de Atendimento à Criança e ao Adolescente, em interface com as demais políticas que articulam o sistema de proteção social à adolescência no Brasil deve ser construída uma nova cultura: o respeito á dignidade do adolescente em cumprimento de medidas socioeducativas.

Esta nova cultura deve ser compreendida e consolidada em todo o Sistema de Garantia de Direitos, a partir de novas práticas institucionais fundamentadas no respeito aos direitos humanos, por todos os atores envolvidos com a socioeducação. Tem base numa compreensão de adolescente como sujeito de direitos, em processo de desenvolvimento e formação de sua sociabilidade, como ser integral, com múltiplas necessidades sociais que devem ser atendidas pela proteção social do Estado.

Nessa perspectiva, ao adolescente que está no processo socioeducativo deverão ser oportunizados processos pedagógicos de caráter emancipador, voltados para a construção da cidadania e da autonomia, em direção à ruptura com a tendência punitiva, que ainda está presente nas unidades de atendimento socioeducativo. A perspectiva pedagógica e emancipatória do atendimento socioeducativo, quer seja em meio aberto ou fechado, exige a formação da consciência crítica sobre a realidade vivenciada, o exercício de seus direitos e deveres e o respeito à dignidade humana dos outros sujeitos com os quais convive, de forma sistemática ou esporádica. Essa pedagogia do socioeducativo possibilita ao adolescente a construção de uma nova visão de mundo, baseada numa noção crítica de homem e de sociedade, com valores e princípios que orientem na perspectiva de projetos de vida libertadores.

Lançando o olhar para o cenário desenhado a partir da análise da legislação e das práticas sociais no âmbito do atendimento socioeducativo, é imperioso reconhecer que existe um fosso entre os direitos proclamados na regulamentação e os direitos materializados nas práticas cotidianas das unidades de atendimento e, inclusive, do Sistema de Garantia de Direitos. Fazer valer a lei exige vencer a impunidade, a segmentação das políticas públicas e a transformação do princípio da prioridade absoluta em uma realidade concreta. Dessa forma, será possível fazer com que os adolescentes em conflito com a lei tenham um futuro, além do período de cumprimento das medidas designadas, com condições de dignidade humana.

Torna-se necessário e urgente construirmos esforços coletivos para oferecer uma cultura de respeito de direitos humanos para os adolescentes em cumprimento de medidas socioeducativas. Apesar de ainda vivenciarmos uma sociedade que não consegue entender os adolescentes como sujeitos de direitos, é fundamental continuar o movimento pela conquista de aliados dispostos 
a colaborar para a desconstrução do discurso de redução da maioridade penal, que a cada dia ganha espaço e adeptos na mídia brasileira. Sem tais mudanças, a cada ato de violência, o medo da sociedade se voltará para alterar os direitos instituídos em lei, em contraposição à ideia de proteção dos direitos dos adolescentes.

\section{REFERÊNCIAS}

BRASIL. Conselho Nacional de Assistência Social. Tipificação Nacional de Serviços Socioassistenciais. Brasília/DF: CNAS, 2009.

Constituição da República Federativa do Brasil. Brasília, DF: Senado Federal, 1988.

Lei 8.069, de 13 de julho de 1990. Dispõe sobre o Estatuto da Criança e do Adolescente e dá outras providências. Diário Oficial da União, Brasília, DF, 13 jul. 1990.

Lei 12.594, de 18 de janeiro de 2012. Institui o Sistema Nacional de Atendimento Socioeducativo (SINASE), Diário Oficial da União, Brasília, DF, 18 jan. 2012.

Ministério do Desenvolvimento Social e Combate à Fome. Política Nacional de Assistência Social. Brasília, DF: Secretaria Nacional de Assistência Social, 2004.

\begin{abstract}
Ministério Público de Minas Gerais. Medidas Socioeducativas: apontamentos sobre a política socioeducativa segundo as diretrizes estabelecidas no Estatuto da Criança e do Adolescente - ECA. Minas Gerais: Central de Apoio Operacional das Promotorias de Justiça da Infância e da Juventude, 2009. Disponível em: <www.mp.mg.gov.br/portal/public/interno/arquivo/ id/3838>. Acesso em: 10 mai. 2013.
\end{abstract}

Secretaria Especial dos Direitos Humanos. Sistema Nacional de Atendimento Socioeducativo - SINASE. Brasília, DF: CONANDA, 2006.

COSTA, Cândida da; MARQUES, Selma Maria Muniz MIRANDA; Aurora Amélia Brito de. Reconstruindo trajetórias de vida? resultados da pesquisa sobre o sistema de atendimento socioeducativo no Maranhão. São Luís: UFMA:SEDH/PR:CONANDA, 2008.

Relatório Seminário: socializando os resultados da pesquisa sobre o sistema de atendimento socioeducativo no Maranhão. São Luís: UFMA:SDH/PR:CONANDA, 2012.

FOUCAULT, Michel. A ordem do discurso. São Paulo: Edições Loyola, 2005.
ISHIDA, V. K. Estatuto da criança e do adolescente: doutrina e jurisprudência. 10. ed. São Paulo: Atlas, 2009.

LIMA JR, Jaime Benevenuto. Os direitos humanos econômicos, sociais e culturais. Rio de Janeiro: Editora Renovar, 2002.

LIMA. F.S.; VERONESE, J.R.P. Medidas sócioeducativas: a responsabilização estatutária como antagônica da visão penal. In: FREIRE, S.M (Org.). Anais do II Seminário Internacional Direitos Humanos, Violência e Pobreza: a situação de crianças e adolescentes na América Latina hoje. Rio de Janeiro: Rede Sírius/UERJ, 2008.

MENDEZ, E. G. Adolescentes e responsabilidade penal: um debate latino-americano. Porto Alegre, 2001. Disponível em: <http://www.abmp.org.br/ textos/2533.htm>. Acesso em: 10 mai. 2013.

SILVA. M. J. Carneiro Jovino da. A centralidade na família no discurso da política de assistência social brasileira: imprecisões, continuidades e rupturas. 2012. Tese (Doutorado em Políticas Públicas). Universidade Federal do Maranhão, São Luís, 2012.

\section{Aurora Amélia Brito de Miranda}

Assistente Social

Doutora em Políticas Públicas pela Universidade Federal do Maranhão (UFMA)

Professora do Departamento de Serviço Social/UFMA

E-mail: aameliabm@uol.com.br

\section{Beatriz Gershenson Aguinsky}

Assistente Social

Doutora em Serviço Social pela Pontifícia Universidade Católica do Rio Grande do Sul (PUC-RS).

Professora do Programa de Pós-Graduação em Serviço Social (PUC-RS)

E-mail: aguinsky@pucrs.br

\section{Cândida da Costa}

Assistente Social

Doutora em Ciências Sociais pela Universidade Federal do Rio Grande do Norte (UFRN).

Professora do Departamento de Serviço Social da Universidade Federal do Maranhão (UFMA)

E-mail: candida.costa@supering.com.br

\section{Lisélen de Freitas Avila}

Assistente Social

Doutoranda do Programa de Pós-Graduação em Serviço Social da Pontifícia Universidade Católica do Rio Grande do Sul (PUC-RS).

E-mail: liselenavila@gmail.com

\footnotetext{
Maria Jacinta Jovino Carneiro da Silva

Assistente Social

Doutora em Políticas Públicas pela Universidade Federal do Maranhão (UFMA)

Professora do Departamento de Serviço Social (UFMA)

E-mail:jacintacjovino@yahoo.com.br
} 
378 Aurora Amélia Brito de Miranda, Beatriz Gershenson Aguinsky, Cândida da Costa, Lisélen de Freitas Avila, Maria Jacinta Jovino Carneiro da Silva e Selma Maria Muniz Marques

\section{Selma Maria Muniz Marques}

Assistente Social

Doutora em Políticas Públicas pela Universidade Federal do Maranhão (UFMA)

Professora do Departamento de Serviço Social/UFMA

E-mail: selmamarqs@yahoo.com.br

\section{Universidade Federal do Maranhão - UFMA}

Cidade Universitária, Av. dos Portugueses,1966,

Bacanga - São Luís / MA

CEP: $65.085-540$

\section{Pontifícia Universidade Católica do Rio Grande do Sul}

\section{- PUC-RS}

Av. Ipiranga, 6681 - Partenon

Porto Alegre - RS

CEP: 90619-900 